\title{
Laser diagnostic experiments on KrF laser ablation plasma-plume dynamics relevant to manufacturing applications*
}

\author{
R. M. Gilgenbach, ${ }^{\dagger}$ C. H. Ching, J. S. Lash, and R. A. Lindley ${ }^{\text {a) }}$ \\ Intense Energy Beam Interaction Laboratory, Nuclear Engineering Department, University of Michigan, \\ Ann Arbor, Michigan 48109-2104
}

(Received 5 November 1993; accepted 5 January 1994)

\begin{abstract}
A brief review is given of the potential applications of laser ablation in the automotive and electronics manufacturing industries. Experiments are presented on $\mathrm{KrF}$ laser ablation of three materials relevant to manufacturing applications: aluminum metal vs aluminum-nitride (AlN) and alumina $\left(\mathrm{Al}_{2} \mathrm{O}_{3}\right)$ ceramics. Plasma and neutral-atom diagnostic data are presented from resonant-holographic-interferometry, dye-laser-resonance-absorption photography, and $\mathrm{HeNe}$ laser deflection. Data show that plasma electron densities in excess of $10^{18} \mathrm{~cm}^{-3}$ exist in the ablation of $\mathrm{AlN}$, with lower densities in $\mathrm{Al}$ and $\mathrm{Al}_{2} \mathrm{O}_{3}$. Aluminum neutral and ion expansion velocities are in the range of $\mathrm{cm} / \mu \mathrm{s}$. Ambipolar electric fields are estimated to be $5-50 \mathrm{~V} / \mathrm{cm}$.
\end{abstract}

\section{INTRODUCTION}

Laser applications to manufacturing have increased dramatically during the past two decades. The first lasers were introduced into automotive manufacturing in 1969; since that time there has been a rapid increase up to about 3000 lasers in the automotive industry in $1991 .{ }^{1}$ Most of the established laser applications in the automotive industry, (e.g., cutting, welding, and drilling) employ $\mathrm{CO}_{2}$ and NdYAG lasers. ${ }^{1}$ The peak intensities of drilling and cutting lasers (especially NdYAG) can exceed $10^{8} \mathrm{~W} / \mathrm{cm}^{2}$, so plasma production is possible, as well as chemical reactions, particularly when assist gases are used.

Excimer lasers have found manufacturing applications in the electronics industry for the drilling of polymers (e.g., polyimide) on multilayer printed circuit boards. ${ }^{2}$ The ultraviolet photons of excimer lasers have proven to be very effective in photoablative decomposition of polymers, resulting in clean etching, with minimal thermal damage; ${ }^{2-4}$ polymer ablation is generally performed at fluences $\left(<1 \mathrm{~J} / \mathrm{cm}^{2}\right)$ below the threshold for plasma production. While less is known about the nonthermal ablation mechanism, ${ }^{5}$ excimer lasers also provide a unique mechanism for clean-hole drilling of ceramics ${ }^{4}$ (at fluences above $1 \mathrm{~J} / \mathrm{cm}^{2}$ ). Below, we present data showing dense plasma emission from $\mathrm{KrF}$ laser ablation of two ceramics (AlN and $\mathrm{Al}_{2} \mathrm{O}_{3}$ ).

An important emerging application of excimer lasers has been laser-ablative deposition of thin films. ${ }^{6-12}$ While known for many years, this material deposition process gained importance beginning in about 1987 with the successful deposition ${ }^{8-10}$ of the high $T_{c}$ superconductor, $\mathrm{YBa}_{2} \mathrm{Cu}_{3} \mathrm{O}_{7-x}$. Since that time, excimer laser ablative deposition has been demonstrated for a wide range of metals $^{7-11}$ and ceramics. ${ }^{6}$ The advantage of excimer laser ablation for deposition of compounds is that the laserablation plume represents a nearly stoichiometric mix of

\footnotetext{
*Paper 4IF1, Bull. Am. Phys Soc. 38, 1982 (1993).

${ }^{\dagger}$ Invited speaker.

a) Present address: Physics Department, University of Sheffield, Sheffield S3 7RH, United Kingdom.
}

the individual atomic components in the target compound, particularly important for ceramics (typically a sintered pellet). The relatively high energy of the plasma ions, compared to thermal-vapor deposition, is believed to improve the properties of the deposited films ${ }^{9}$ (particularly better adhesion $^{6}$ ).

An important emerging application of laser-ablation plasmas is as a soft $\mathbf{x}$-ray source for lithography in microelectronics circuit fabrication. Experiments in this area are ongoing at Sandia National Laboratories Livermore (SNLL), using $\mathrm{KrF}$ lasers with intensities $\left(10^{11}-10^{12}\right.$ $\left.\mathrm{W} / \mathrm{cm}^{2}\right)$ and fluences $\left(5000 \mathrm{~J} / \mathrm{cm}^{2}\right)$ that are much higher than those typically utilized for drilling or deposition. ${ }^{12}$ Structures with $0.1 \mu \mathrm{m}$ dimensions have been generated on PMMA (polymethylmethacrylate) by using $14 \mathrm{~nm}$ soft $\mathrm{x}$-rays from the SNLL laser plasma experiment. ${ }^{12}$

Recent experiments at a number of laboratories ${ }^{13-17}$ have applied plasma diagnostics to understand the fundamental mechanisms of moderate-intensity $\left(10^{8}-10^{10}\right.$ $\mathrm{W} / \mathrm{cm}^{2}$ ) laser ablation processing of metals and ceramics. Deflection of a helium-neon laser probe beam ${ }^{13}$ and pulsed laser schlieren photography ${ }^{13}$ have yielded important information on plasma and neutral density gradients in vacuum and background gas up to atmospheric pressure. Laser-induced fluorescence has been employed to follow the temporal evolution of a single selected species of atom or molecule; ${ }^{16,17}$ hook spectroscopy has also been employed. ${ }^{17}$ In the past several years, experiments at the University of Michigan (UM) have concentrated on species-resolving diagnostics which can image a particular atom, molecule, or ion population either photographically ${ }^{14}$ or holographically. ${ }^{15,18}$ The first of these diagnostics is dye-laser-resonance-absorption-photography (DLRAP or resonant shadowgraphy) in which a dye laser probing wavelength is tuned to a resonance absorption line of a particular atom (typically aluminum ground state neutral atoms) or molecule (e.g., $\mathrm{CN}$ from ablation of polyimide) $;{ }^{14} \mathrm{Al}^{+}$ions have also been imaged (below) by this diagnostic. Most recently, the real part of the index of refraction of laser ablation plumes has been measured near an atomic resonance line by resonant-holographic- 


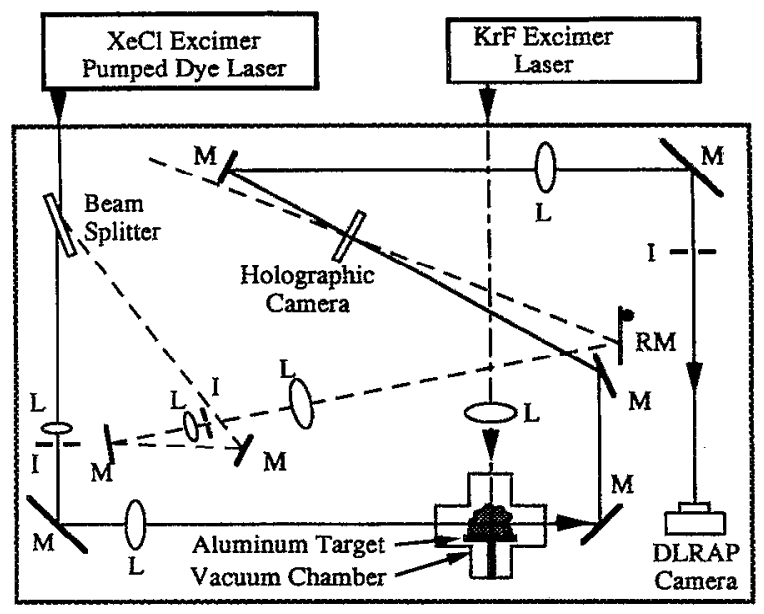

(a)

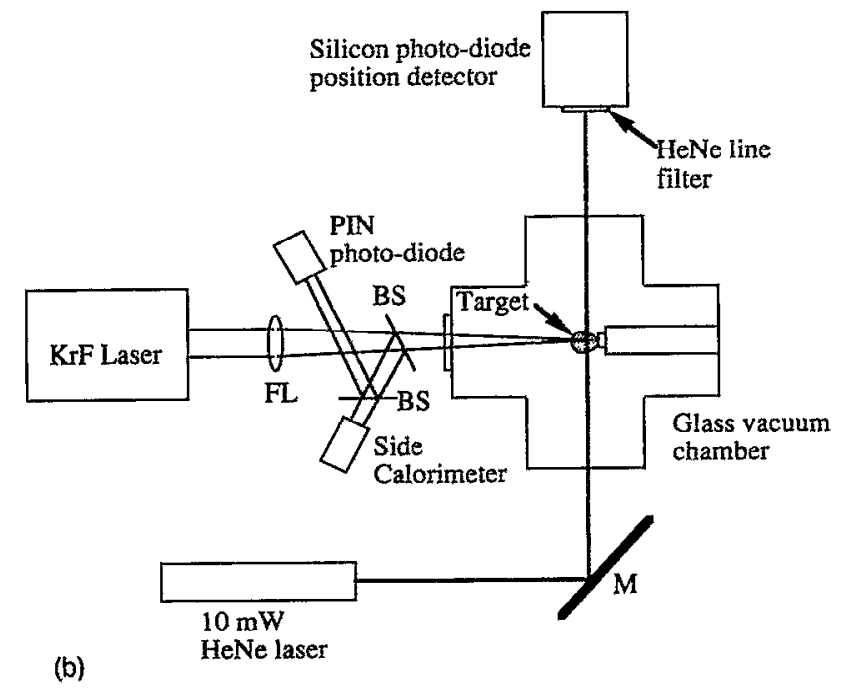

FIG. 1. Experimental configurations. (a) Resonant-holographic interferometry and dye-laser-resonance-absorption photography. (b) Laser deflection diagnostic. Definitions of symbols: $M=$ mirror, $L=$ lens, $R M$ $=$ rotatable mirror, $I=$ iris, $B S=$ beam splitter, $F L=$ focusing lens, DLRAP $=$ dye-laser-resonance-absorption photography.

interferometry (RHI) in order to measure the absoluteline-density profile of a single-species (aluminum neutrals). ${ }^{15,18}$ Others have used quadrupole-mass-spectrometers and direct particle detection to identify laserablated species from ceramics and polymers. ${ }^{5}$

Since two of the future industrial applications of excimer lasers are expected to be in the machining and deposition of metals ${ }^{7,11}$ and ceramics, ${ }^{6}$ we present here a study of the plasma/neutral dynamics of laser ablation of three materials which have importance to clectronics and automotive manufacturing: aluminum metal, alumina $\left(\mathrm{Al}_{2} \mathrm{O}_{3}\right.$ ceramic) and aluminum nitride (AlN).

\section{EXPERIMENTAL CONFIGURATIONS FOR DIAGNOSTIC STUDIES OF LASER ABLATION OF METALS AND CERAMICS}

The experimental configurations are depicted in Fig. 1. Schematic illustrations of the setup for dye-laserresonance-absorption photography ${ }^{14}$ and resonant- holographic interferometry ${ }^{15,18}$ are shown in Fig. 1(a). The ablation source is a $\mathrm{KrF}$ excimer laser (Lumonics) which generates $248 \mathrm{~nm}$ radiation with per-pulse energy typically less than about $0.8 \mathrm{~J}$ with a pulse length of $40 \mathrm{~ns}$. The $\mathrm{KrF}$ laser radiation is focused $\left(1-7 \mathrm{~J} / \mathrm{cm}^{2}\right)$ onto a target in a chamber evacuated by a turbomolecular pump. Incident laser energy is adjusted by inserting quartz plates into the $\mathrm{KrF}$ laser beam. These quartz plates have little effect on the focal spot, which is typically about $2.3 \times 2.3$ $\mathrm{mm}$. Calorimetry is performed during all experimental runs.

The diagnostic laser is a XeCl-laser-pumped dye laser (Lambda Physik FL3002) with a 20 ns pulse length. The dye laser beam is expanded and split for resonant holographic interferometry. The probe and reference beams are recombined on a holographic plate (Agfa-Gevaert 8E56), with a pathlength difference less than the coherence length (about $5 \mathrm{~cm}$ ). The two-pulse holographic technique is used, in which a mirror is rotated slightly between pulses to produce reference fringes. The theory of resonant holographic interferometry is given in several of the references, ${ }^{15,18-22}$ so it is not reproduced here; the dye laser wavelength is tuned near $(<0.02 \mathrm{~nm})$ the resonance line of the desired species (typically the $394.401 \mathrm{~nm} \mathrm{Al}$ ground state neutral transition). For large enough dye-laser detuning from the resonance line, the fringe shifts are proportional to the density of this selected species; at smaller detuning a theory has been developed at the University of Michigan, which accounts for the finite dye laser bandwidth and temperature $(0.3 \mathrm{eV}$ for Al neutrals in Ref. 18). For dye-laser-resonance-absorption photography, only the probe beam is incident on the open-shutter camera, which uses Type 47 Polaroid film. ${ }^{14}$

Figure 1(b) shows the configuration for He-Ne laser deflection, which has been utilized in this article to measure plasma electron density gradients. ${ }^{13}$ The $10 \mathrm{~mW}$ $\mathrm{He}-\mathrm{Ne}$ beam passes parallel to the target surface, perpendicular to the $\mathrm{KrF}$ beam. The HeNe beam deflection is measured by a quadrant detector (with two sides shorted) coupled to a fast rise-time ( $25 \mathrm{~ns}$ ) amplifier circuit. The magnitude of the deflection angle is given by the equation ${ }^{13}$

$$
\Delta \Phi=K L \operatorname{grad}(n),
$$

where $K=K_{n}=5.24 \times 10^{-23} \mathrm{~cm}^{3}$ for Al neutrals, and $K=K_{e}=-1.79 \times 10^{-22} \mathrm{~cm}^{3}$ for electrons, and $L$ is the path length.

Thus, the detector signal is directly proportional to the electron or neutral density gradient, depending upon the direction of the deflection (polarity of the signal). This diagnostic sensitivity is 3.4 times greater for electrons than for neutrals. Only deflection data at early times, for the polarity of clectron contributions are presented here. The spacing between the HeNe beam and the surface can be adjusted to obtain the spatial profile of the density gradient; these data may be integrated to yield the density. ${ }^{13}$

\section{EXPERIMENTAL RESULTS}

In this section, we present diagnostic data from recent $\mathrm{UM}$ experiments on $\mathrm{KrF}$ laser ablation of aluminum, alu- 

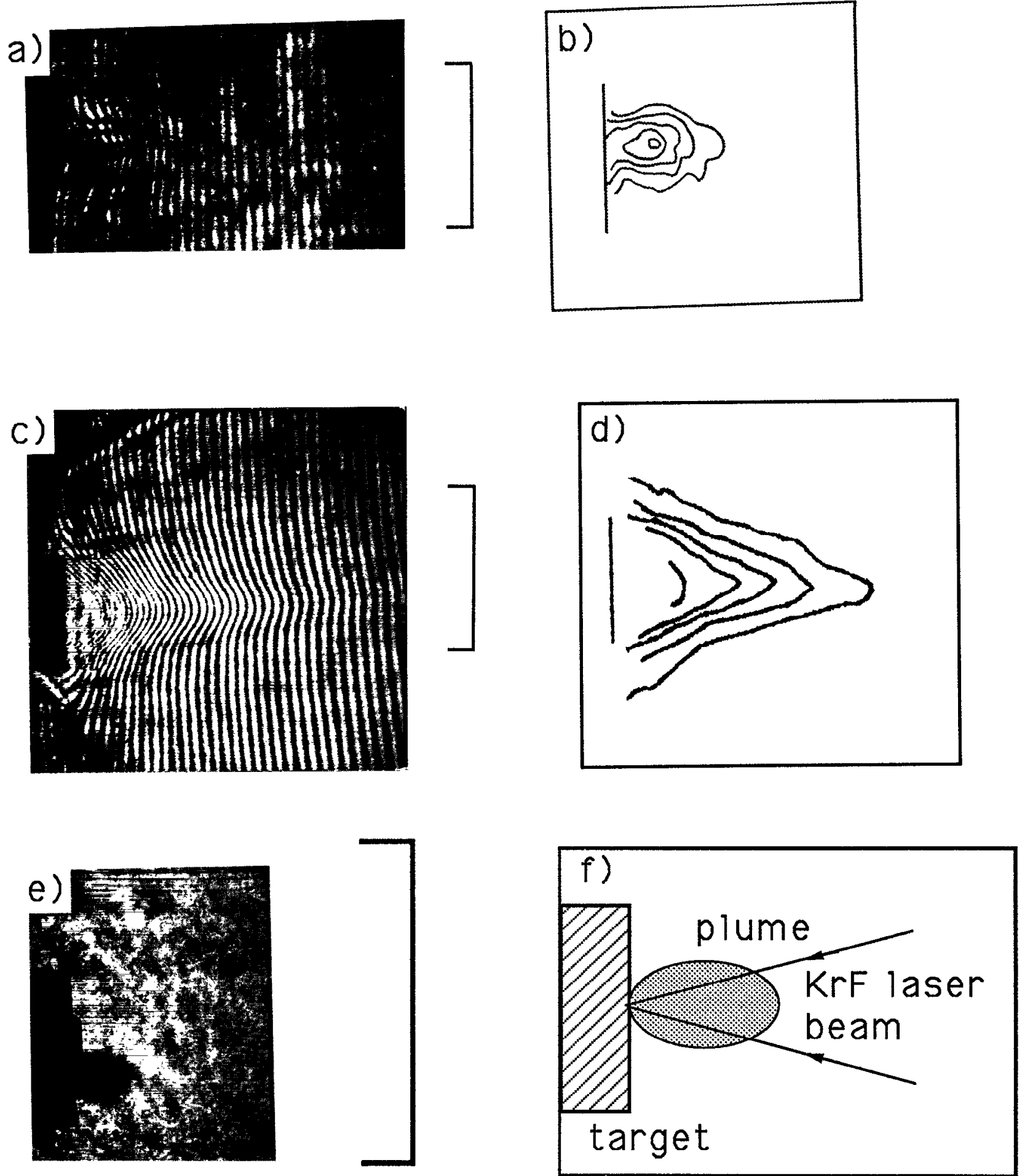

FIG. 2. Resonant diagnostic data for $\mathrm{KrF}$ laser ablation of $\mathrm{Al}, \mathrm{Al}_{2} \mathrm{O}_{3}$, and $\mathrm{AlN}$ targets. Bars in (a)-(b), (c)-(d), and (e) indicate $1 \mathrm{~cm}$. (a) Resonant-holographic-interferogram of $\mathrm{KrF}$ laser ablated Al neutral atom plume from $\mathrm{Al}$ target in vacuum; fluence of $2.4 \mathrm{~J} / \mathrm{cm}^{2}$; delay between lasers of $0.70 \mu \mathrm{s}$ and dye-laser detuning of $\Delta \lambda=+0.004 \mathrm{~nm}$ from line center. (b) Equi-line-density contours of Al neutrals ablated from Al target for interferogram of (a). Starting with outer contour, line densities are $4.3 \times 10^{13} \mathrm{~cm}^{-2} ; 9 \times 10^{13} \mathrm{~cm}^{-2} ; 1.4 \times 10^{14} \mathrm{~cm}^{-2} ; 1.9 \times 10^{14} \mathrm{~cm}^{-2}$; inner contour is $2.5 \times 10^{14} \mathrm{~cm}^{-2}$. (c) Resonant-holographic-interferogram of $\mathrm{KrF}$ laser ablated $\mathrm{Al}$ neutral atom plume from $\mathrm{Al}_{2} \mathrm{O}_{3}$ target in vacuum; delay between lasers of $0.82 \mu \mathrm{s}$ and dye-laser detuning $\Delta \lambda=-0.018 \mathrm{~nm}$ from line center. $\mathrm{KrF}$ laser fluence of $4.1 \mathrm{~J} / \mathrm{cm}^{2}$. (d) Equi-line-density contours of Al neutrals ablated from $\mathrm{Al}_{2} \mathrm{O}_{3}$ target for interferogram of (c). Starting with outer contour, line-densities are: $4.5 \times 10^{14} \mathrm{~cm}^{-2} ; 8.9 \times 10^{14} \mathrm{~cm}^{-2} ; 1.3 \times 10^{15} \mathrm{~cm}^{-2} ; 1.8 \times 10^{15}$ $\mathrm{cm}^{-2}$; inner contour is $2.7 \times 10^{13} \mathrm{~cm}{ }^{2}$. (e) Dye-laser-resonance-absorption photograph of $\mathrm{Al}^{+}$ions from $\mathrm{KrF}$ laser ablation of AlN target, dye laser tuned to $490.28 \mathrm{~nm} \mathrm{Al}^{+}$absorption line. $\mathrm{KrF}$ laser fluence of $3.1 \mathrm{~J} / \mathrm{cm}^{2}$. Delay time between lasers of $0.19 \mu \mathrm{s}$. (f) Schematic illustration of diagnostic geometry. 


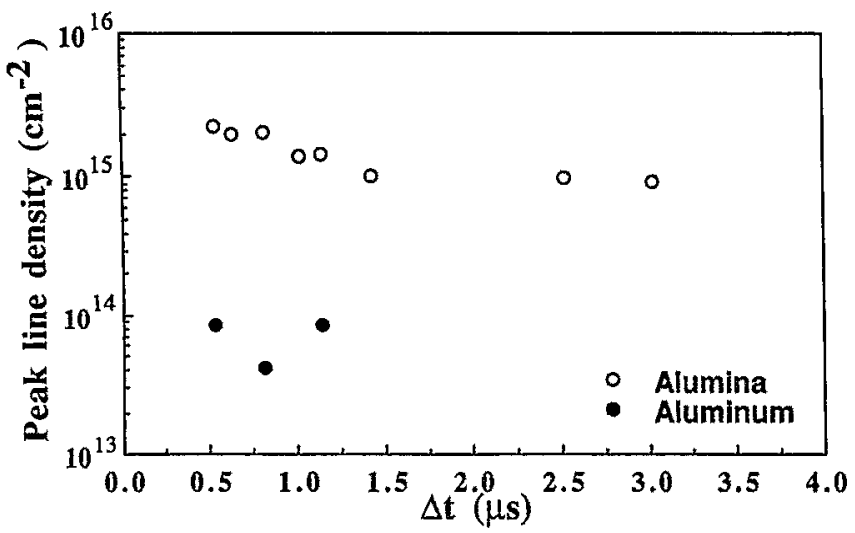

FIG. 3. Peak Al ground-state, neutral-atom line-density measured in vacuum by resonant-holographic interferometry for $\mathrm{KrF}$ laser ablation of Al target (filled circles) and alumina (open circles). $K_{r F}$ laser fluence of $4.1-4.7 \mathrm{~J} / \mathrm{cm}^{2}$.

mina, and aluminum-nitride. Resonant-holographic interferometry data of $\mathrm{Al}$ ground-state-neutral atoms are presented in Fig. 2 for ablation of $\mathrm{Al}$ and $\mathrm{Al}_{2} \mathrm{O}_{3}$ targets; DLRAP data are presented for an AIN target. The laserablation diagnostic geometry is presented in Fig. 2(f). The reconstructed interferograms in Figs. $2(\mathrm{a})$ and $2(\mathrm{c})$, are interpreted to give equi-line-density contours of $\mathrm{Al}$ neutral atoms, as shown in Figs. 2(b) and 2(d).

The interferogram and equi-line-density contours in Figs. 2(a) and 2(b) for ablation from Al targets measure peak Al-neutral line densities up to about $2.5 \times 10^{14} \mathrm{~cm}^{-2}$ (the peak line-densities from other data are generally less than $10^{15} \mathrm{~cm}^{-2}$ ). The total number of aluminum neutral atoms from laser ablation of Al metal has been determined from equi-line-density contours, similar to Fig. $2(\mathrm{~b})$, to be about $3 \times 10^{14}$. From a time-sequence of such interferograms, the Al neutral atom expansion velocity has been measured $^{18}$ in the range of $0.5-1 \mathrm{~cm} / \mu \mathrm{s}$, similar to that measured below with DLRAP.

Figures 2(c) and 2(d) present interferogram and equiline-density contours of $\mathrm{Al}$-neutral atoms for $\mathrm{KrF}$ laser ablation of an $\mathrm{Al}_{2} \mathrm{O}_{3}$ ceramic target. The major difference between $\mathrm{Al}_{2} \mathrm{O}_{3}$ target data and $\mathrm{Al}$ target data is that the aluminum neutral atom line density is a factor of 10-20 times higher for $\mathrm{Al}_{2} \mathrm{O}_{3}$ targets [peak of $2.7 \times 10^{15} \mathrm{~cm}^{-2}$ in Figs. 2(c) and (d)]. Al neutral line-density measurements versus time are presented in Fig. 3 for $\mathrm{Al}$ versus for $\mathrm{Al}_{2} \mathrm{O}_{3}$ targets. Reasons for this difference in $\mathrm{Al}$ neutral densities for metals versus ceramics will be discussed in the next section.

A dye-laser-resonance-absorption photograph (490.28 $\mathrm{nm} \mathrm{Al-II} \mathrm{line)} \mathrm{of} \mathrm{the} \mathrm{Al}^{+}$ion plume from $\mathrm{KrF}$ laser ablation of AlN is presented in Fig. 2(e). The most significant difference in laser ablation of AlN from the other cases was that mostly $\mathrm{Al}^{+}$ions were observed rather than the dense Al neutral plume.

Dye-laser-resonance-absorption photography has been employed to measure the position versus time (for expansion velocity) on a sequence of laser ablated plumes of $\mathrm{Al}$

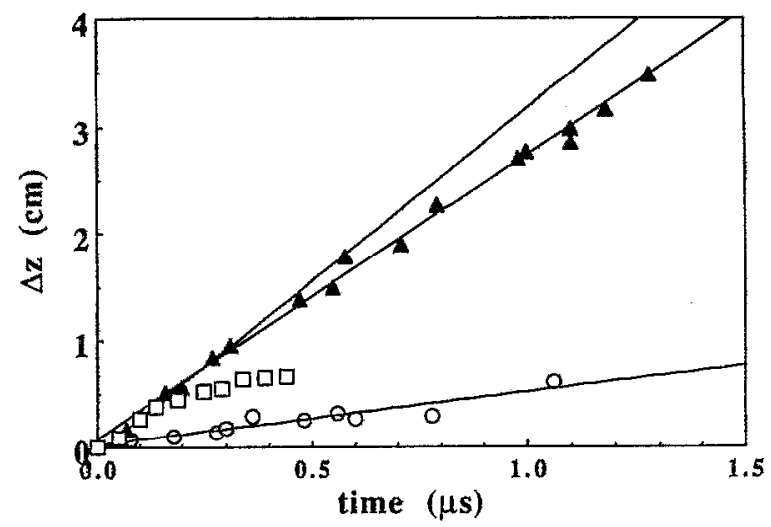

FIG. 4. Data obtained from DLRAP diagnostic of plume position (perpendicular to target) versus time used to find initial expansion velocities of $\mathrm{KrF}$ laser ablated $\mathrm{Al}$ atoms and $\mathrm{Al}^{+}$ions. Lines show initial slopes used to determine initial expansion velocities for $\mathrm{Al}^{+}$ablated from $\mathrm{AlN}$ target (squares); Al neutrals ablated from $\mathrm{Al}$ target (circles) and $\mathrm{Al}_{2} \mathrm{O}_{3}$ target (triangles). Slopes indicate velocities: $3.2 \mathrm{~cm} / \mu \mathrm{s}\left(\mathrm{Al}^{+}\right.$from AIN target), $3.0 \mathrm{~cm} / \mu \mathrm{s}$ (Al neutrals from $\mathrm{Al}_{2} \mathrm{O}_{3}$ target), and $0.5 \mathrm{~cm} / \mu \mathrm{s}$ (Al neutrals from Al metal target). KrF laser fluence of: $1.9-2.2 \mathrm{~J} / \mathrm{cm}^{2}$ for $\mathrm{Al}$ and $\mathrm{Al}_{2} \mathrm{O}_{3}$ targets; $2.5-3.1 \mathrm{~J} / \mathrm{cm}^{2}$ for AlN target.

neutrals and $\mathrm{Al}^{+}$ions. Figure 4 gives a plot of $\mathrm{Al}$ neutral position from different laser pulses versus time for $\mathrm{Al}$ and $\mathrm{Al}_{2} \mathrm{O}_{3}$ targets, as well as $\mathrm{Al}^{+}$ion expansion from $\mathrm{AIN}$ ablation. It can be seen from the initial slope of the plots in Fig. 4 that the $\mathrm{Al}^{+}$initial velocity $(3.2 \mathrm{~cm} / \mu \mathrm{s})$ from $\mathrm{AlN}$ ablation is similar to the $\mathrm{Al}$ neutral velocity from $\mathrm{Al}_{2} \mathrm{O}_{3}$ targets $(3.0 \mathrm{~cm} / \mu \mathrm{s})$; Al targets $(0.5 \mathrm{~cm} / \mu \mathrm{s})$ give a lower velocity of Al neutrals at these moderate fluences (1.9-3.1 $\mathrm{J} / \mathrm{cm}^{2}$ ).

Electron density gradients were measured as a function of time by the $\mathrm{HeNe}$ laser deflection diagnostic for $\mathrm{KrF}$ laser ablation of $\mathrm{Al}, \mathrm{Al}_{2} \mathrm{O}_{3}$, and $\mathrm{AIN}$ targets. Figure 5 gives typical density gradient data versus time after the peak of

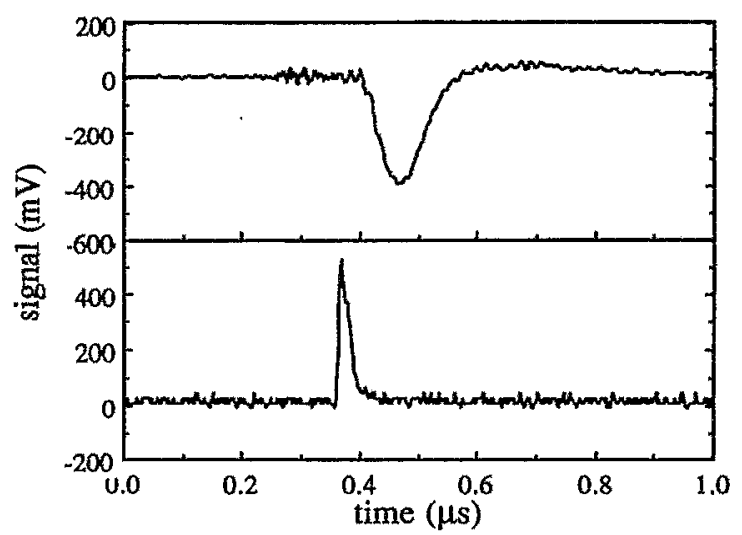

FIG. 5. Typical data. Top trace: HeNe laser deflection signal from $\mathrm{KrF}$ laser ablation of $\mathrm{Al}_{2} \mathrm{O}_{3}$ at a fluence of $4 \mathrm{~J} / \mathrm{cm}^{2}$. HeNe laser beam is $0.8 \mathrm{~mm}$ from target surface. Negative signal corresponds to electrons; positive signal corresponds to neutral atom contribution. Bottom trace: $\mathrm{KrF}$ laser pulse detected by PIN diode. Note that the deflection signal has a $20 \mathrm{~ns}$ throughput delay from the amplifier circuit, which has not been compensated in the traces. 


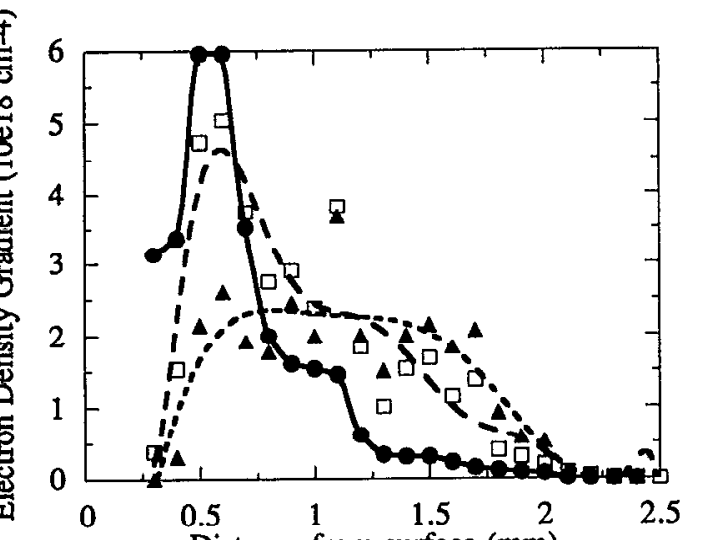

(a)

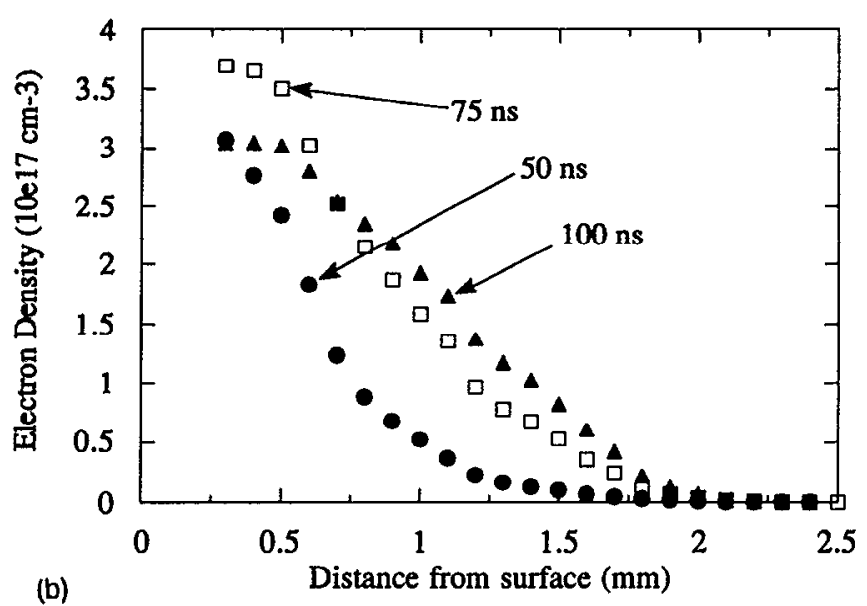

(b)

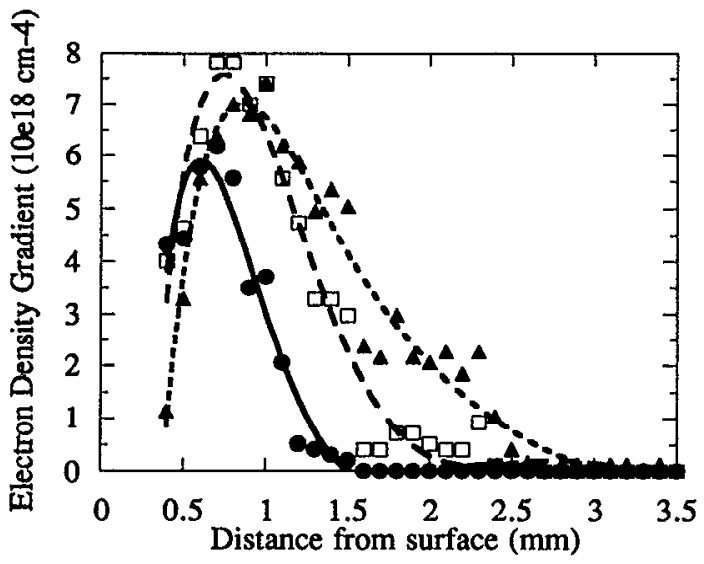

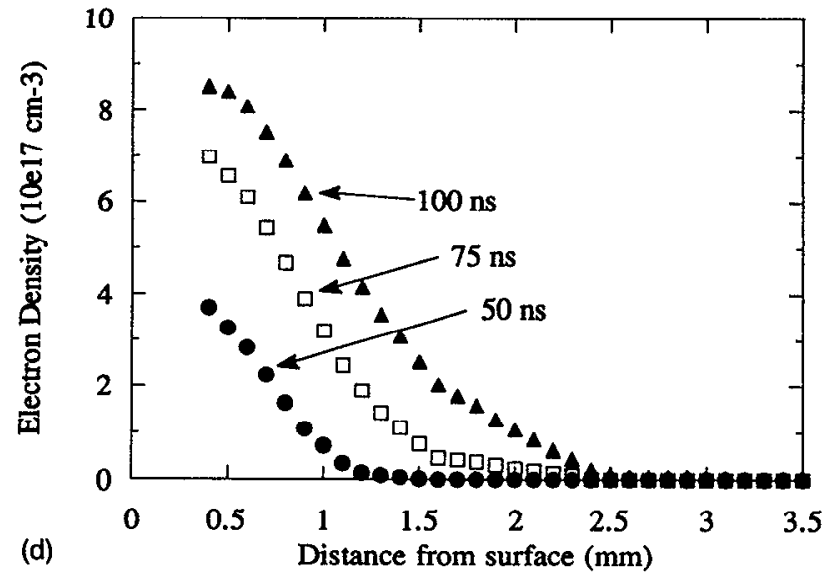

(e)
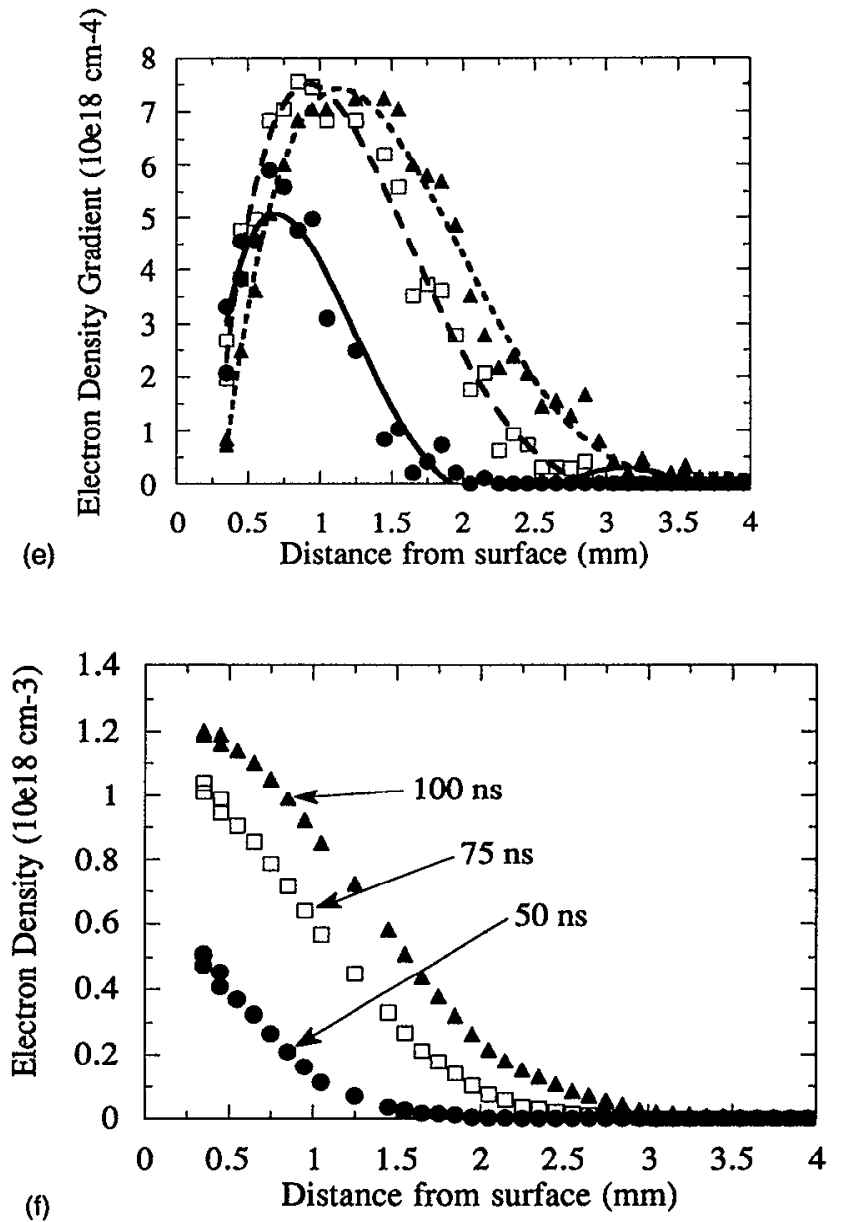

FIG. 6. Laser deflection data on $\mathrm{KrF}$ laser ablated materials at times after the peak of the $\mathrm{KrF}$ laser pulse: $50 \mathrm{~ns}$ (circles), $75 \mathrm{~ns}$ (squares), and 100 ns (triangles) after the peak of the $\mathrm{KrF}$ laser pulse. $\mathrm{KrF}$ laser fluence of $4 \mathrm{~J} / \mathrm{cm}^{2}$. (a) Electron density gradient of laser ablated Al target. (b) Electron density of laser ablated $\mathrm{Al}$ target obtained from integration of (a). (c) Electron density gradient of laser ablated $\mathrm{Al}_{2} \mathrm{O}_{3}$ target. (d) Electron density of laser ablated $\mathrm{Al}_{2} \mathrm{O}_{3}$ target obtained from integration of (c). (e) Electron density gradient of laser ablated AlN target. (f) Electron density of laser ablated AlN target obtained from integration of (e).

the $\mathrm{KrF}$ laser pulse obtained from the laser deflection diagnostic; position is measured at the edge of the plume in the direction normal to the target. Early-time signals ( $<100 \mathrm{~ns})$ are dominated by the large-amplitude deflection caused by plasma electrons. At later times, (100-200 ns), the contribution from the slower neutral plume is detected.

By shifting the HeNe probe beam away from the sur- face on subsequent laser pulses, the electron density gradient can be measured as a function of position and time. Figure 6(a) presents electron density gradients from ablation of $\mathrm{Al}$ targets at three early times $(50,75$, and $100 \mathrm{~ns}$ after the peak of the $\mathrm{KrF}$ laser pulse). The peak density gradient passes the probe beam at $50 \mathrm{~ns}$, after which the gradient moves out and flattens with time. The density 
gradient data of Fig. 6(a) represent raw data which are indicative of the typical experimental data scatter. By integrating the data of Fig. 6(a), one can obtain the density profiles as a function of time, as in Fig. $6(\mathrm{~b})$. The peak electron density measured at a distance of $0.3 \mathrm{~mm}$ is about $3.7 \times 10^{17} \mathrm{~cm}^{-3}$. This dense plasma only extends out to about $2 \mathrm{~mm}$ from the target surface. The position of the electron density gradient peak moves at a velocity from about $0.7-1.9 \mathrm{~cm} / \mu \mathrm{s}$.

Electron density measurements from $\mathrm{KrF}$ laser ablated $\mathrm{Al}_{2} \mathrm{O}_{3}$ are presented in Fig. 6(c), along with the integrated density profile, in Fig. $6(\mathrm{~d})$, at three early times. In these data, the peak electron density is about $8 \times 10^{17} \mathrm{~cm}^{-3}$ (higher than the Al metal target), at $0.3 \mathrm{~mm}$ from the target surface. The peak of the electron density gradient moves away from the target at a velocity of $0.6-1.8 \mathrm{~cm} / \mu \mathrm{s}$.

Electron density gradient measurements from $\mathrm{KrF}$ laser-ablated AIN are presented in Figs. 6(e) and 6(f). The important difference in the AlN target case is that the peak electron density (at $0.3 \mathrm{~mm}$ ) is much higher (about $1.2 \times 10^{18} \mathrm{~cm}^{-3}$ ), than the other two targets. The expansion velocity of the electron density gradient peak is about $0.5-2 \mathrm{~cm} / \mu \mathrm{s}$.

\section{DISCUSSION AND ANALYSIS}

Excimer laser ablation from metals is generally assumed to be a thermal mechanism. ${ }^{16}$ Ablation from insulators is a clearly different mechanism, particularly when the photon energy ( $5 \mathrm{eV}$ for $\mathrm{KrF}$ ) is less than the bandgap of the dielectric ( $7.4 \mathrm{eV}$ for $\mathrm{Al}_{2} \mathrm{O}_{3}, 5.9-6.2 \mathrm{eV}$ for AlN $)^{5,16,23}$ Dickinson has proposed that laser ablation of wide-bandgap dielectrics occurs when metal atoms or ions are desorbed because of defects in the material. ${ }^{5}$

For the cold-pressed $\mathrm{Al}_{2} \mathrm{O}_{3}$ pellets utilized in this study, there probably exists a large concentration of defects, which effectively lower the bandgap. The factor of 10-20 higher aluminum neutral-atom line densities from $\mathrm{Al}_{2} \mathrm{O}_{3}$ targets compared to $\mathrm{Al}$ targets could have several possible explanations. The most obvious effect is that the reflectivity of the $\mathrm{Al}_{2} \mathrm{O}_{3}$ ceramic ( $R \sim 2 \%$ from our rough measurements at $308 \mathrm{~nm}$ ) is much lower than for $\mathrm{Al}$ targets $(R=92 \%$ ), equivalent to a 12 times larger absorbed fluence on the ceramic. (It should be noted that the melting temperature of $\mathrm{Al}$ is $660^{\circ} \mathrm{C}$, whereas $\mathrm{Al}_{2} \mathrm{O}_{3}$ ceramic melts at $2030^{\circ} \mathrm{C}$, so a purely thermal ablation mechanism is unlikely for the ceramic.) The ultraviolet laser radiation also penetrates more deeply into the ceramic than the metal, possibly liberating more $\mathrm{Al}$ atoms.

The causes of high density $\mathrm{Al}^{+}$ion emission from $\mathrm{AlN}$ ablation are not understood at this time. These may be a consequence of the molecular bonding of the AIN. The fact that the ejected Al ions and neutrals from the ceramics have a higher velocity than the neutrals from the metal could be a consequence of their different ablation mechanism, as well as the slightly higher fluence. It is expected that ions are accelerated by the ambipolar electric field and that charge-exchange collisions yield fast neutrals. The apparent slowing of the $\mathrm{Al}^{+}$ions at later times in Fig. 4 could

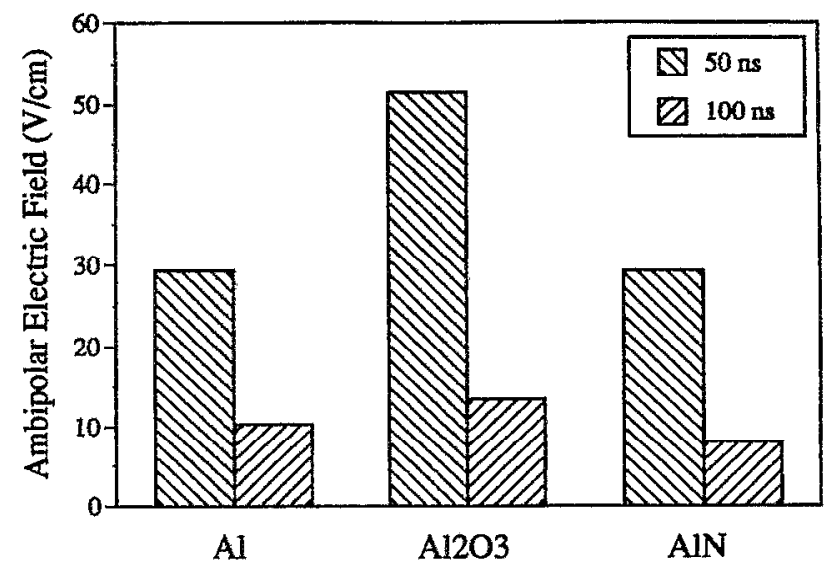

FIG. 7. Ambipolar electric field inferred from data of Fig. 6 according to Eq. (2).

be due to ion-electron recombination or surface-charging of the AlN target.

Estimates have been made of the ambipolar electric field, based on the electron density gradient measurements, by use of the equation, ${ }^{24}$

$$
E_{a}=\left[\left(D_{i}-D_{e}\right) /\left(\mu_{i}+\mu_{e}\right)\right][\operatorname{grad}(n) / n],
$$

where $D_{i}$ and $D_{e}$ are the ion and electron diffusion coefficients, $\mu_{i}$ and $\mu_{e}$ are the ion and electron mobilities, and $n$ is the plasma density. These estimates are presented in Fig. 7 , assuming a plasma temperature of about $1 \mathrm{eV}$ (typical of laser plasmas at these moderate intensities of $10^{8}-10^{9}$ $\left.\mathrm{W} / \mathrm{cm}^{2}\right){ }^{25-28}$ It can be seen that the ambipolar electric fields found, $5-50 \mathrm{~V} / \mathrm{cm}$, would accelerate ions to $0.5-5$ $\mathrm{eV}$, over a $1 \mathrm{~mm}$ distance. These ion energies are consistent with the high energy ions diagnosed by others. ${ }^{9,25}$

\section{CONCLUDING REMARKS AND FUTURE DIRECTIONS FOR LASERS IN MANUFACTURING}

Laser ablation is finding an increasing number of applications relevant to manufacturing processes. Highdensity plumes of plasma electrons, ions, and neutral atoms have been characterized by species-resolving diagnostics. While a great deal of research has been performed on high-power laser-plasma interactions, ${ }^{29}$ there is a need for future theoretical-modeling research on the basic mechanisms of moderate intensity $\left(10^{8}-10^{10} \mathrm{~W} / \mathrm{cm}^{2}\right)$ laser ablation. ${ }^{26-27}$ Future theoretical work will need to extend the laser absorption mechanism into the material surface, particularly in ceramics.

It is interesting to speculate on the new applications which may result from advanced laser technologies, e.g., copper vapor lasers, ${ }^{30,31}$ and diode-pumped NdYAG lasers. In particular, experiments at Lawrence Livermore National Lab have shown a number of advantages of high power $(0.5-1 \mathrm{~kW})$ copper vapor lasers with highrepetition rates $(4-5 \mathrm{kHz})$ for machining of metals: ${ }^{30}$ (1) near diffraction-limited spots $(10-100 \mu \mathrm{m}),(2)$ small heat-affected zone (shown by continuous grain structure to 
the edge of holes), and (3) high processing speeds. The role of plasmas in machining by these short-pulse, highpower copper vapor lasers requires further study.

\section{ACKNOWLEDGMENTS}

We would like to thank A. Edson and C. Pae for assistance in the lab and in preparation of this manuscript. Previous contributions in the lab by P. L. G. Ventzek are gratefully acknowledged. The authors would like to acknowledge valuable discussions and information provided by the following scientists: Y. Y. Lau, M. Brake, J. Sell, B. Braren, B. Warner, P. Weber, and G. Kubiak. Comments of the referee were very useful.

This research was supported by National Science Foundation Grant No. CTS-9108971. J.S.L. was supported by a National Science Foundation Fellowship. R.A.L. received support from a DoE MFET Fellowship.

'D. M. Roessler, in Proceedings of the International Conference on Lasers 91, San Diego, CA, 1991, edited by F. J. Duarte and D. G. Harris (S.T.S., MacLean, VA, 1992), p. 514.

${ }^{2}$ Proceedings of Lasers in Microelectronic Manufacturing Conference. San Jose, CA, 1991, edited by B. Braren (SPIE, Bellingham, WA, 1991), Vol. 1598.

${ }^{3} \mathrm{R}$. Srinivasan, in Laser Processing and Diagnostics, edited by D. Bauerle (Springer-Verlag, Berlin, 1984), Vol. 39.

${ }^{4} \mathrm{G}$. D. Poulin, P. A. Eisele, and T. A. Znotins, in Proceedings of OE'LASE 88, Los Angeles, CA (SPIE, Bellingham, WA, 1988), Vol. 1023, p. 202; H. J. Kahlert, U. Sowada, and D. Basting, ibid.

5J. T. Dickinson, S. C. Langford, L. C. Jensen, and P. A. Eschbach, J. Appl. Phys. 68, 1831 (1990); R. F. Haglund, M. Affatigato, J. Arps, and K. Tang, in Laser Ablation Mechanisms and Applications, edited by J. C. Miller and R. F. Haglund (Springer-Verlag, Berlin, 1991), Vol. 389 , p. 246.

${ }^{6} J$. Sell (private communication, 1993); G. L. Doll, J. A. Sell, C. A. Taylor, and R. Clarke, Phys. Rev. B 43, 6816 (1991).

${ }^{7}$ A. Sugerman and B. Braren, in Proceedings of OE'LASE 93, Los Angeles, 1993, edited by B. Braren and M. N. Libenson (SPIE, Bellingham, WA, 1993), Vol. 1856, p. 19.

${ }^{8}$ T. Venkatesan, X. D. Wu, A. Inam, Y. Jeon, M. Croft, E. W. Chase, C. C. Chang, J. B. Wachtman, R. W. Odom, F. Radicati di Brozolo, and C. A. Magee, Appl. Phys. Lett. 53, 1431 (1988).

${ }^{9}$ J. P. Zheng, Z. Q. Huang, D. T. Shaw, and H. S. Kwok, Appl. Phys. Lett. 54, 280 (1989); A. N. Zherikin, V. N. Bagratashvili, O. V. Boyarkin, and V. N. Burimov, in Proceedings of OE'LASE 93, Los Angeles, 1993 edited by B. Braren and M. N. Libenson (SPIE, Bellingham, WA, 1993), Vol. 1856, p. 92.
${ }^{10}$ S. R. Foltyn, P. Tiwari, R. C. Dye, M. Q. Le, and X. D. Wu, Appl. Phys. Lett. 63, 1848 (1993); K. Murakami, in Laser Ablation of Electronic Materials, edited by E. Fogarassy and S. Lazare (Elsevier, Amsterdam, 1992), p. 125.

${ }^{11}$ H.-U. Krebs and O. Bremert, Appl. Phys. Lett. 62, 2341 (1993).

${ }^{12}$ G. Kubiak (private communication, 1993).

${ }^{13}$ C. L. Enloe, R. M. Gilgenbach, and J. Meachum, Rev. Sci. Instr. 58, 1597 (1987); P. L. G. Ventzek, R. M. Gilgenbach, J. Sell, and D. Heffelfinger, J. Appl. Phys. 68, 965 (1990); 70, 587 (1991); J. A. Sell, D. M. Heffelfinger, P. Ventzek, and R. M. Gilgenbach, Appl. Phys. Lett. 55, 2435 (1989).

${ }^{14}$ R. M. Gilgenbach and P. L. G. Ventzek, Appl. Phys. Lett. 58, 1597 (1991); P. L. G. Ventzek, R. M. Gilgenbach, C. H. Ching, and R. A. Lindley, J. Appl. Phys. 72, 1696 (1992).

${ }^{15}$ R. A. Lindley, R. M. Gilgenbach, and C. H. Ching, Appl. Phys. Lett. 63, 888 (1993).

${ }^{16}$ R. W. Dreyfus, R. Kelly, and R. E Walkup, Appl. Phys. Lett. 49, 1478 (1986); R. W. Dreyfus, J. Appl. Phys. 69, 1721 (1991); R. J. von Gutfeld and R. W. Dreyfus, Appl. Phys. Lett. 54, 1212 (1989); J. E. Rothenburg and R. Kelly, Nucl. Instrum. Methods Phys. Res. B 1, 291 (1984); R. Kelly and J. E. Rothenburg, Nucl. Instrum. Methods Phys. Res. B 7/8, 755 (1985).

${ }^{17}$ A. D. Sappey and T. K. Gamble, Appl. Phys. B 53, 353 (1991); J. Appl. Phys. 72, 5095 (1992); A. D. Sappey, T. K. Gamble, and D. K. Zirkle, Appl. Phys. Lett. 62, 564 (1993).

${ }^{18} \mathrm{R}$. A. Lindley, Doctoral dissertation, University of Michigan, 1993.

${ }^{19}$ G. V. Dreiden, A. N. Zaidel', G. V. Otrovskaya, Y. I Ostrovskii, N. A. Pobedonostseva, L. V. Tanin, V. N. Fippov, and E. N. Shedova, Sov, J. Plasma Phys. 1, 256 (1975).

${ }^{20} \mathrm{H}$. Odenthal and J. Uhlenbusch, IEEE Trans. Plasma Sci. PS-8, 431 (1980).

${ }^{21}$ R. M. Measures, Appl. Opt. 9, 737 (1970).

${ }^{22}$ W. C. Marlow, Appl. Opt. 6, 1715 (1967).

${ }^{23}$ W. D. Kingsley, H. K. Bowen, and D. R. Uhlmann, Introduction to Ceramics (Wiley, New York, 1976), 2nd ed.

${ }^{24}$ F. F. Chen, Plasma Physics and Controlled Fusion (Plenum, New York, 1984), 2nd ed., p. 159.

${ }^{25}$ J. F. Ready, Effects of High Power Laser Radiation (Academic, New York, 1971).

${ }^{26} \mathrm{~S}$. Gitomer, R. D. Jones, and C. Howsare, Proceedings of EO'LASE 89 (SPIE, Bellingham, WA, 1989), Vol. 1066, p. 145.

${ }^{27}$ R. Goldman (private communication, 1993).

${ }^{28}$ M. L. Brake, J. Meachum, R. M. Gilgenbach, and W. Thornhill, IEEE Trans. Plasma Sci. PS-15, 73 (1987).

${ }^{29}$ W. L. Kruer, The Physics of Laser Plasma Interactions (AddisonWesley, Redwood City, CA, 1988).

${ }^{30}$ B. Warner and P. Weber (private communication, 1993).

${ }^{31}$ J. S. Lash and R. M. Gilgenbach, Rev. Sci. Inst. 64, 3308 (1993); also: P. L. G. Ventzek and R. M. Gilgenbach, J. Appl. Phys. 72, 3080 (1992). 